\title{
Leuprorelin depot injection: patient considerations in the management of prostatic cancer
}

\author{
Zinelabidine Abouelfadel ${ }^{1,2}$ \\ E David Crawford' \\ 'Urologic Oncology, University of \\ Colorado Cancer Center, Aurora, \\ CO, USA; ${ }^{2}$ Currently, Amiri Hospital \\ Kuwait University, Urology Section, \\ Kuwait City
}

\begin{abstract}
Hormone therapy is well established for treating patients with prostate cancer and remains the mainstay of the treatment of metastatic and locally advanced disease, this article reviews the rationale for its use, its different forms, and complications and controversies still surrounding some of its modalities. Availability of long-acting synthetic luteinizing hormonereleasing hormone (LHRH) agonists revolutionized the hormonal treatment of prostate cancer, and helped to avoid the emotional and psychological effects related to surgical castration. The depot formula has gained wide acceptance from both patients and physicians. This review emphasizes the newer, long-acting formula, leuprorelin (leuprolide acetate), especially the 6-month formula, its advantage over over shorter-acting depot products, and its potential to become a standard of care for patients eligible for androgen deprivation therapy.
\end{abstract}

Keywords: prostate cancer, androgen deprivation therapy (adt), leuprorelin

\section{Introduction}

In the post prostate-specific antigen (PSA) era, screening for prostate cancer has not only led to a stage migration, but also to a higher incidence of the disease. Such a trend has decreased the incidence of metastatic disease at diagnosis and paralleled the decrease in the mortality rate from prostate cancer.

The incidence of metastatic disease was only $1.6 \%$ of patients enrolled in the Cancer of the Prostate Strategic Urologic Research Endeavor (CaPSURE), diagnosed between 1998 and 2003 (Ryan et al 2006). On the other hand the population failing the initial treatment is increasing, and $40 \%$ of the patients treated with curative intent eventually end up with PSA recurrence (Ward and Moul 2005), raising the question of whether there is any evidence that aggressive intervention in these patients may result in cure.

Because many patients with T3 disease or local lymph node metastases progress to distant metastases, some authors recommended that the concept of advanced prostate cancer should also include stages C and D1 (Moul 2004) (T3, T4, and any T N1).

Today, in addition to its well-established role in treating patient with metastatic disease, androgen deprivation therapy (ADT) is sometimes used to treat patients with biochemical failure even without evidence of local or systemic recurrence. This therapy is also used as an adjunct to radiation for high risk localized disease.

The treatment of locally advanced and metastatic prostate cancer is only palliative, and most patients who respond initially to ADT ultimately evolve towards hormone refractory disease within 2 years, and at this stage, unfortunately, alternative modalities such as chemotherapy become of limited value, with a survival of only 18-24 months. 
This inevitable evolution led to new strategies being explored for delaying progression to androgen independence, which may involve targeting of anti-apoptotic factors, use of chemotherapy at the time of androgen ablation, or blockage or down-regulation of androgen receptor (AR) activity (Petrylak 2005). Among those novel options is a broad range of promising strategies such as targeting signal transduction pathways, cell cycle regulation and differentiation, and angiogenesis (Cavarretta et al 2005).

\section{Prostate cancer: a hormone sensitive malignancy}

The prostate - testis relationship has been known since the 18th century when John Hunter (Androutsos 1998) demonstrated in 1786 that castration in young male animals prevented further growth of the prostate, whereas in the adult it caused atrophy. Hunter also observed that aging eunuchs never suffered from symptoms of a hypertrophied prostate (Home 1811).

The second half of the 19th century marked a growing interest in orchiectomy for the treatment of prostatic hyperplasia, particularly urinary retention. Symptomatic improvement in over half of patients with an enlarged prostate treated with castration was reported by William White in 1895 and 1904 (White 1895, 1904).

The development of prostate cancer requires the presence of a prostate gland and a source of androgens. It has been shown that androgens produced elsewhere can be activated in the prostatic tissue, as prostate cancer never occurs in those with testicular feminization syndrome and in patients with 5-alfa reductase deficiency (Newling 1996).

Before 1940s there was no effective treatment for advanced prostate cancer. In 1939 Charles Huggins, aware of androgens sensitivity of the prostate gland, proposed orchiectomy to control prostate cancer. He demonstrated that castration decreased the height of prostatic epithelial cells in normal prostatic tissue, and that testosterone administration stimulated the secretory activity of dogs' prostatic cells (Huggins and Clark 1940); furthermore, he proved that castration produced clinical pain relief and a stabilization or regression of metastatic osseous lesions (Huggins et al 1941) and reduction in acid phosphatase level (Huggins and Hodges 1941). Huggins soon realized, however, that the same results could be achieved by the less drastic procedure of the administration of female sex hormones to neutralize the effect of androgens produced by the testicles. Consequently, in 1941 he began to inject his patients with the hormones stilbestrol and hexestrol.
Other forms of castration have been developed, such as the technique of radio-orchiectomy (Keyes and Ferguson 1936), consisting of irradiation of the testis in patients with advanced prostate cancer.

Ninety to $95 \%$ of the androgens are produced by the testes and only $5 \%-10 \%$ by the adrenals. These small amounts of androgens continue to support tumor growth.

The involvement of the adrenal gland in hormonal control of prostate malignancies was supported by reports of an increase in the urinary concentration of 17-keto-steroids in patients after castration (Satterthwaite et al 1941; Schröder 2002). The recognition of the role of adrenal androgens in prostate cancer led to the development of the therapeutic strategy known as combined androgen blockade.

The early form of this approach combined orchiectomy and bilateral adrenalectomy. The first procedure in a patient with prostate cancer was carried out by Huggins and William Wallace Scott in 1945 (Huggins and Scott 1945), who demonstrated a clinical benefit of such procedure in men with disease recurrence after orchiectomy.

The initial success of hormonal therapy led on the one hand to less interest in radical surgical and radiation treatment, even for localized disease. On the other hand, it led to a tendency to remove sound organs with vital functions such as adrenals (adrenalectomy) and the pituitary gland (surgical ablation [Silverberg and Britt 1979]) and external irradiation (Murphy and Schwippert 1951) of the pituitary gland, as well as the implantation of radioactive material (Fergusson 1957), in hope of completely suppressing androgens and therefore curing or slowing disease progression.

Schally and associates (1971) purified the decapeptide gonadotropin-releasing hormone, referred to as LHRH. The availability of long-acting synthetic luteinizing hormonereleasing hormone (LHRH) agonists in the 1980s revolutionized the hormonal treatment of prostate cancer, enabling many men to avoid the emotional and psychological effects of surgical castration (McLeod 2003).

Anti-androgens block testosterone action in target tissues by interfering with testosterone or dihydrotesterone (DHT) binding to the steroid-binding domain of the androgen receptor. Steroidal anti-androgens, such as cyproterone acetate, also have some ability to block luteinizing hormone (LH) secretion, and are therefore associated with many of the sexual effects seen with LHRH agonists (See 2003).

By contrast, the non-steroidal anti-androgens have been associated with a far more beneficial sexual side effect profile. Non-steroidal anti-androgens, such as flutamide, were first used in the mid 1970s (Sogani et al 1975) and steroidal 
anti-androgens such as cyproterone acetate were approved for use in the 1980s (Jacobi 1983).

The gonadotropin-releasing hormone (GnRH) antagonists represent the newest class of agents introduced for the hormonal treatment of prostate cancer. The advantages of GnRH antagonists are that they do not cause the initial surge in testosterone associated with LHRH agonists and they rapidly achieve castrate androgen levels.

In clinical trials, monotherapy with abarelix was shown to achieve medical castration more rapidly than leuprorelin (leuprolide acetate) alone or in combination with bicalutamide and without an early surge in testosterone (Trachtenberg et al 2002).

\section{Physiology: hypothalamus - pituitary - testis axis}

LHRH, also known as GnRH, is secreted in a pulsatile fashion by the hypothalamus. The increase in LHRH stimulates the anterior pituitary to secrete LH and follicle-stimulating hormone into the systemic circulation (Denmeade and Isaacs 2004). LH stimulates the Leydig cells of the testes to secrete testosterone.

Testosterone is converted into a more potent compound, DHT. Conversion occurs in the cytoplasm of prostatic cells by the enzyme 5-alfa reductase. In addition to testosterone, adrenal androgens may be converted to DHT (Sandow et al 1988). In the cytosol, DHT binds to the androgen receptor and crosses into the nucleus. The activated androgen receptor binds to specific DNA sequences that influence gene expression, stimulate the synthesis of specific proteins such as PSA, and trigger cell proliferation.

In the normal prostate, androgen is the major growth factor through two mechanisms: on the one hand, it stimulates cellular proliferation of prostatic epithelial cells; on the other, it blocks the potentially high apoptotic rate of epithelial cells. The net balance determines the overall number of prostate cells (Isaacs 1984, 1994).

\section{Testosterone-lowering strategies (Table I)}

The first method of permanent castration was bilateral orchiectomy, and the first reversible method was diethylstilbestrol (DES) (Byar and Corle 1988).

Therapeutic approaches to interrupt the production and/or block the action of testosterone include:

(1) Suppression of testosterone via surgical removal of the testes or use of estrogens;

Table I Methods to interrupt the production of and/or block the action of testosterone

\begin{tabular}{|c|c|c|}
\hline Methods & Action & Side effects \\
\hline Orchiectomy & $\begin{array}{l}\text { Surgical suppression of testicular male hormones leading } \\
\text { to immediate drop in testosterone (Iversen 1998) }\end{array}$ & $\begin{array}{l}\text { Limitations include its irreversible nature causing } \\
\text { erectile dysfunction, occasional post-operative } \\
\text { complications, and associated psychological factors } \\
\text { (Cassileth 1989) }\end{array}$ \\
\hline Estrogens & $\begin{array}{l}\text { The negative feedback on the hypothalamus afforded by } \\
\text { estrogen. Suppression of LHRH release and subsequent } \\
\text { decrease not only of LH but also of FSH (Brawer 200I) }\end{array}$ & $\begin{array}{l}\text { Cardiovascular complications. gynecomastia is a } \\
\text { common complaint }\end{array}$ \\
\hline LHRH agonists & $\begin{array}{l}\text { Over-stimulation of the LHRH receptors, followed by } \\
\text { subsequent drop due to the loss the pulsatile secre- } \\
\text { tion pattern (LSG 1984); the net effect is a reduction of } \\
\text { testosterone to castration levels within } 2-4 \text { weeks }\end{array}$ & Testosterone surge and potential for clinical flare \\
\hline LHRH antagonists & $\begin{array}{l}\text { Inhibition of LHRH and subsequent rapid time to } \\
\text { testosterone suppression with a higher rate of medical } \\
\text { castration (Debruyne 2004) }\end{array}$ & $\begin{array}{l}\text { - Safety of abarelix is comparable to that of LHRH } \\
\text { agonists with or without anti-androgen } \\
\text { - Cost } \\
\text { - Increased liver enzymes }\end{array}$ \\
\hline Anti-androgens & $\begin{array}{l}\text { Block the binding of DHT to the androgen receptors in } \\
\text { the prostate (Iversen } 200 \mathrm{I} \text { ) }\end{array}$ & $\begin{array}{l}\text { Gynecomastia, breast pain } \\
\text { Diarrhea,visual disturbances }\end{array}$ \\
\hline Inhibitors of alfa-reductase & $\begin{array}{l}\text { Inhibit 5-alfa reductase conversion of testosterone to } \\
\text { DHT in the prostate }\end{array}$ & Gynecomastia, breast pain, anemia \\
\hline Ketoconazole & $\begin{array}{l}\text { In high dose is able to produce castrate levels of andro- } \\
\text { gens (both testicular and adrenal) within } 4-8 \mathrm{~h} \text { of the } \\
\text { first dose (Lowe 1990) }\end{array}$ & $\begin{array}{l}\text { Gastrointestinal disturbances and suppression of } \\
\text { cortisol production which resulted in subsequent } \\
\text { Addisonian crisis and sudden death (Pont 1987) }\end{array}$ \\
\hline
\end{tabular}

Abbreviations: DHT, dihydrotesterone; LH, luteinizing hormone; LHRH, luteinizing hormone-releasing hormone; FSH, follicle-stimulating hormone. 
(2) LHRH agonists to down-regulate the pituitary and prevent release of LH or by using LHRH antagonists to directly suppress LH release;

(3) Inhibition of 5-alfa reductase conversion of testosterone to DHT in the prostate;

(4) Blocking the binding of DHT to the androgen receptors in the prostate.

These strategies can be used individually or in various combinations.

In 1983, ketoconazole in high dose was identified as able to produce castrate levels of androgens within 4-8 h of the first dose (Trachtenberg and Point 1983), and represents an alternative treatment where urgent androgen ablation is required (Lowe and Bamberger 1990).

\section{Biological effects of androgen deprivation \\ Anterior pituitary - testis axis}

With longer-term administration, a resetting of the anterior pituitary receptor occurs, with subsequent reduction in $\mathrm{LH}$ along with follicle-stimulating hormone (FSH) release, resulting in achievement of castrate levels of testosterone (Conn et al 1984). Chronic exposure to LHRH ultimately suppressed testosterone by desensitizing pituitary cells through down-regulation of the LHRH receptors (Van Loenen et al 2002).

Castration, the time-honored frontline treatment for metastatic prostate cancer, was previously defined by induction of a serum testosterone level of $<50 \mathrm{ng} / \mathrm{mL}$ (Coppage and Cooner 1965; Young and Kent 1968). Recent literature redefines this upper limit as $<20 \mathrm{ng} / \mathrm{mL}$ (Oefelein et al 2000).

\section{Prostate cell level}

Effects of androgen deprivation include apoptosis of both cancer cells and benign prostatic epithelium (Denmead et al 1996; Buttyan et al 2000). One of the earliest events, occurring prior to the initiation of epithelial apoptosis, is degeneration of the prostatic vasculature. This has been observed in animal models as well as in the human prostate (FranckLissbrant et al 1998; Shabisgh et al 1999). A recent study has shown that in patients on complete androgen blockade therapy $(\mathrm{CAB})$, there were morphological changes within the prostatic tissues as early as 7 days after initiating ADT, similar to the response to castration. These changes induce significant involution within prostatic tissues over 7-28 days, but allow the persistence of some viable tumor cells capable of proliferation (Mercader et al 2007). This event is mediated at least in part by decreased expression of vascular endothelial growth factor (VEGF), an androgen-regulated gene, in the prostatic epithelium and stroma (Burchardt et al 2000). This phenomenon of apoptosis does not affect basal cells which remain intact. A high percentage of androgenindependent cancers appear to maintain expression of the AR gene, but many have genetic alterations that change receptor activity. Altered expression of AR co-activators may occur in recurrent cancer, and AR mutations may occur in as many as $40 \%-50 \%$ of such cancers. Proteins involved in cell survival and resistance to apoptosis are over-expressed in androgen-independent prostate cancer cells or tumors (Peehl 2001).

\section{Indication of ADT in prostate cancer}

Today, in addition to its well-established role in treating patients with metastatic disease, ADT is sometimes used to treat patients with biochemical failure even without evidence of local or systemic recurrence. This therapy is also used as an adjunct in patients undergoing radiation for high-risk localized disease.

\section{Controversies around hormonal therapy}

Several controversies still surround the modalities of this therapy (Table 2):

- Monotherapy or CAB?

- Early versus delayed?

- Continuous or intermittent?

- Adjuvant or neoadjuvant?

- Secondary manipulation after failure of initial hormonal therapy?

- Hormone after PSA recurrence?

- Hormone for localized prostate cancer.

- Role of anti-androgens alone?

- Role of anti-5AR + antiandrogens?

\section{LHRH agonists flare issue}

During the initial 1-2 weeks the LHRH receptor is overstimulated, initially resulting in testosterone surge and potential for clinical flare. There is a delay in testosterone reduction and a surge in testosterone and dihydro-testerone as well as elevation of PSA. Symptomatic flare may result. The impact of the increase in FSH is only now undergoing evaluation, but this too may have an untoward effect on prostatic carcinoma. The flare phenomenon may be life threatening if an LHRH agonist is administered to men with high-volume metastatic disease. The clinical consequence of the flare is prevented by pretreatment with an anti-androgen, which inhibits the 
Table 2 Controversies around hormonal therapy for prostate cancer

\begin{tabular}{|c|c|}
\hline HT modality & Argument for \\
\hline arly vs delayed HT & $\begin{array}{l}\text { The appropriate time to initiate hormonal therapy for prostate } \\
\text { cancer remains a matter of debate. } \\
\text { Two recent studies provide convincing clinical evidence support- } \\
\text { ing the early treatment of advanced prostate cancer (Kirk 2000; } \\
\text { Messing 1999). } \\
\text { The randomized trial reported by the Medical Research Council } \\
\text { (MRC) has shown more rapid local and distant disease progression } \\
\text { in the deferred treatment group, increase in serious complications, } \\
\text { such as pathologic fractures, spinal cord compression, and there wa } \\
\text { clear survival advantages associated with early hormone therapy for } \\
\text { high risk malignancies (MRC 1997). } \\
\text { Also in Eastern Cooperative Oncology Group (ECOG)/SWOG } \\
\text { Stage DI (N+) study (Messing 1999), the survival in the delayed } \\
\text { therapy and immediate theapy arms was } 65 \% \text { and } 85 \% \text { r respetivel }\end{array}$ \\
\hline
\end{tabular}

$\mathrm{CAB}$

Intermittent hormone therapy

Anti-androgen alone
From 1980 to 1991, approximately 36 prospective, randomdesigned with at least I year of therapy. Of these, only 3 showed a statistically significant improvement in overall survival (Crawford 1989; Denis 1998).

Although the overall benefit of MAB may be small, some patients will likely show a more substantial improvement in survival compared with androgen suppression alone. Should remain a reasonable option when discussing treatments for metastatic prostate cancer (Messing 1999).

A recent Japanese study showed that first-line combination LHRH-agonists therapy with bicalutamide $80 \mathrm{mg}$ in patients with advanced prostate cancer offered significant benefits over LHRHA alone, with respect to TTTF,TTP, although the difference in the interim overall survival was not statistically significant (Usami 2007).

This option became feasible only when medical castration became available. Advantages include reduction of side effects from therapy such as the physiological changes associated with castration, reduction of cost, and potentially delayed emergence of hormone refractoriness as evidenced by laboratory data (Sandford 1984).

The most recent evidence is the mature experience of phase II trial from Ottawa group. Intermittent AS therapy was initiated in prostate-cancer patients to delay hormone resistance and minimize potential side effects of androgen-deprivation therapy (Malone 2007). Intermittent AS has also the potential to reduce side effects, including recovery of hemoglobin level, return of sexual function and absence of weight gain at the end of the study period (Malone 2005). Its use in DI and D2

prostate cancer patients appears to be safe and feasible. Off treatment periods are $>40 \%$ and contribute to patients' quality of life (Miller 2007).

Monotherapy with bicalutamide $150 \mathrm{mg}$ once daily provides a survival outcome that is not significantly different to that of castration in men with locally advanced, non-metastatic disease, while conferring significant advantages for sexual interest and physical capacity (Boccon-Gibod 1997; Pavone-Macaluso 1994). ized studies were performed, 27 of them being reasonably well

\section{Argument against}

Arguments for early hormonal therapy are countered, however, by a number of factors, including:

- The long natural history for most men of rising PSA levels before clinical metastases and death

- No randomized controlled clinical trials to confirm the survival advantage or to document the longterm effects of such therapy.

The side effects of hormone therapy, particularly for younger men

- Cost of hormone treatment, particularly if over a long period of time.

Studer et al (2006) has shown that there is no benefit in early versus delayed treatment in patients with clinically localized prostate cancer not suitable for radical therapy.

The lack of benefit in any of the other 24 studies led to much debate about the overall benefit of MAB in men with metastatic disease.

The survival benefit for MAB of only $3 \%$ has led many experts to believe that the benefit is overshadowed by the therapy cost and side effects (Chodak 2004, 2005).

Controversy remains as to which patients might benefit the most from intermittent hormonal therapy, when to start hormonal therapy, how long to treat before stopping, and when to restart subsequent cycles.

The most common side effects of non-steroidal antiandrogen monotherapy are gynecomastia and male breast pain. These events occur more frequently than with castration alone (McLeod 1997; Migliari 1999). 
Table 2 (Continued)

\begin{tabular}{ll}
\hline HT modality & Argument for \\
\hline & $\begin{array}{l}\text { The administration of low-dose flutamide (I25 mg) was clinically } \\
\text { effective in treating PSA recurrence after definitive treatments for } \\
\text { prostate cancer, and was well tolerated (Barqawi 2003). }\end{array}$ \\
$\begin{array}{l}\text { Anti-androgen } \\
\text { and Inhibition }\end{array}$ & $\begin{array}{l}\text { The combination of finasteride and flutamide showed a moder- } \\
\text { of 5-alfa }\end{array}$ \\
reductase & therapy. The efficacy appears to be greater in patients who can \\
& achieve a PSA nadir of 0. I ng/mL or less after the start of treat- \\
& ment (Barqawi 2003). \\
& This combination is also regarded as a potency-sparing therapy. \\
It is inevitable that the overwhelming majority of men treated \\
with pharmacologic or surgical castration will develop disease \\
progression due to development and propagation of androgen- \\
independent prostate cancer cells. Although it offers modest \\
activity, it represents an alternative to early use of chemotherapy \\
in patients with androgen independent disease.
\end{tabular}

Secondary HT The strategy can be summarized as follow either the adjunction second-line non-steroidal anti-androgens or its withdrawal in case of initial $C A B$, the use of inhibitors of adrenal androgen production such as ketoconazole (Scholz 2005).

The future direction would involve the development of molecules that effectively inhibit androgen receptor through changes in the ligand binding complex activating conformational changes or co-factor recruitment (Small 2006).

Preclinical evidence supports the hypothesis that FSH signaling contributes to progression of AIPC. Patients on LHRH agonists have modestly reduced but detectable FSH levels, whereas patients treated with orchiectomy have significantly elevated FSH levels. Abarelix suppresses FSH more effectively than LHRH agonists when used as front-line hormonal therapy (Beer 2004).

PSA-only Recurence after Radical Prostatectomy

\footnotetext{
Androgen deprivation as monotheraphy for localized prostate cancer
}

Moul et al in a large retrospective multi-center study, found that delayed hormonal therapy in high-risk disease (GS $>7$ and PSA DT $<12$ months) was associated with an approximately 2 -fold increased risk of metastasis (Moul 2004).

Whoever this study has the limitations of retrospective studies and requires validation to reach a meaningful result (Freedland 2005).

Primary ADT has long been the treatment of choice for localized and locally advanced prostate cancer in Japan and more evidence of its efficacy is accumulating. This trend is also on the rise in clinical practice in the USA (Akaza 2006).

More evidence has been accumulating that progression of prostate cancer was retarded by primary hormone therapy in men with localized or locally advanced prostate cancer (Akaza et al 2006).

Some authors described that triple androgen blockade (LHRH agonist+anti-androgens) therapy followed by finasteride maintenance appears to be a promising for management of localized prostate cancer (Labrie 2002), and long-term and continuous $C A B$ offers the possibility of long-term control or possible cure of localized prostate cancer (Janoff 2005).
Argument against

Although the side effects are low, combined finasteride and flutamide therapy significantly lowers hemoglobin and haematocrit levels in men with advanced prostate cancer (Ornstein 1999).

Longevity following progression has historically been short, with a reported median of 6-9 months, given the lack of efficacious treatment options (Taneja 2003). With the development of potentially efficacious chemotherapeutic regimens, particularly taxane-based chemotherapies, secondary manipulation may delay therapy (Petrylak 2007).

Retrospective study, revealed that patients with PSA recurrence who did not undergo hormonal deprivation therapy had a median actuarial time to metastasis of 8 years after PSA rise, only $34 \%$ had apparent metastases (Pound 1999).

HT provides no benefit or might even harm men with low-risk/local disease (Leibovitz 200I).

ADT resulted in poor control of localized prostate cancer. In particular, younger patients and those with Gleason $\geq 6$ cancers were at higher risk of treatment failure.

And the toxicity, principally in the form of bone fractures, was high (Janoff 2005).

Androgen deprivation as a primary therapy for localized prostate cancer provided modest disease control, but toxicity was high. Younger men with tumors of Gleason score $\geq 6$ had a higher risk of biochemical progression (Kirk 2006). 
Table 2 (Continued)

\begin{tabular}{|c|c|c|}
\hline HT modality & Argument for & Argument against \\
\hline Adjuvant $\mathrm{HT}$ & $\begin{array}{l}\text { NAS can reduce the number of tumor clonogens prior to radiation, } \\
\text { thus increasing the tumor control probability.Also, NAS may sensi- } \\
\text { tize tumor cells to radiation if cell kill by both modalities follows a } \\
\text { common pathway. The timing and sequence of NAS and radiation } \\
\text { are important, with radiation being most effective if given at the } \\
\text { point of maximal tumor regression (Zietman } 2000 \text {; Hall } 2000 \text { ). } \\
\text { Pilepich showed that the incidence of local failure at } 10 \text { years was } \\
23 \% \text { in the adjuvant arm, compared with } 38 \% \text { in the radiation } \\
\text { alone The } 10 \text {-year rate of distant metastases was } 24 \% \text { in the adju- } \\
\text { vant arm, compared with } 39 \% \text { in the control arm ( }<0.000 \text { I) } \\
\text { and concluded that adjuvant androgen suppression reduces dis- } \\
\text { ease progression and improves survival in patients with unfavor- } \\
\text { able-risk, high-grade prostate cancer treated with radiotherapy } \\
\text { (Pilepich 2005). }\end{array}$ & $\begin{array}{l}\text { The } 5 \text {-year bRFS rate for patients with unfavorable } \\
\text { tumors who received radiation doses of } 72 \text { Gy or } \\
\text { greater vs less than } 72 \text { Gy was } 75 \% \text { and } 4 \text { I \%, respec- } \\
\text { tively; thus the benefit might not be due to adding } \\
\text { hormone to higher radiation dose (Lyons } 2000 \text { ). There } \\
\text { appeared to be little if any benefit of adding neoadju- } \\
\text { vant AS before high intensity focused ultrasound for } \\
\text { men with presumed organ-confined prostate cancer } \\
\text { (Uchida 2006). } \\
\text { Neo-adjuvant and adjuvant HT before radical } \\
\text { prostatectomy showed a significant reduction in } \\
\text { the positive surgical margin rate, from } 23 \% \text { to I } 2 \% \\
\text { (p = 0.0I) for patients who received } 3 \text { vs } 8 \text { months } \\
\text { of neoadjuvant AST, but no cancer control outcomes } \\
\text { (Gleave } 200 \text { I). A recent study to evaluate NHT } \\
\text { prior to radical prostatectomy for high-risk prostate } \\
\text { cancer, showed that biochemical failure was frequent } \\
\text { after this combined treatment, even in a PTO ca } \\
\text { which questions the use of modality in this category } \\
\text { of patients (Tabata 2006). }\end{array}$ \\
\hline
\end{tabular}

Abbreviations: ADT, androgen deprivation therapy; AIPC, androgen-independent prostate cancer; $A S$, androgen suppression; $D H T$, dihydrotesterone; $C A B$, complete androgen blockade; HT, hormone therapy; LH, luteinizing hormone; LHRH, luteinizing hormone-releasing hormone; $F S H$, follicle-stimulating hormone; MAB, maximum androgen blockade; $N A S$, neoadjuvant androgen suppression; NHT, neoadjuvant hormonal therapy; PSA, prostate-specific antigen;TTTF,. time-to-treatment failure; TTP, time-to-disease progression.

stimulatory effect of the testosterone surge at the level of the androgen receptor (Thompson 2001).

Patients with symptomatic advanced prostate cancer such as those with significant obstructive voiding symptoms merit a flare-free induction of hormonal therapy, as do patients with significant back pain and early neurologic sequelae: both urinary retention and paraplegia are side effects to be avoided.

Optimal blockade is achieved by pretreatment with an appropriate agent (eg, anti-androgen), or for the patient in whom maximum blockade is desirable immediately, consideration could be given to the use of ketoconazole, which dramatically reduces testosterone in only a matter of hours.

\section{Failure to achieve castrate level}

A small but potentially important subgroup of men on depot LHRH agonist therapy fail to achieve or maintain a castrate level of testosterone (Oefeien and Comum 2000), a finding that supports the need for monitoring testicular response during LHRH agonist therapy (Morote et al 2006).

\section{Cost of treatment}

For an individual patient the cost of LHRH agonist treatment surpassed the cost of surgery at less than 4.2-5.3 months, and for combined androgen blockade (LHRH agonists and non-steroidal anti-androgens) at less than 2.7-3.4 months (Mariani et al 2001). Except for patients with short anticipated survival, current medical androgen suppressive treatment options are more costly than bilateral orchiectomy.

For men who accept it, bilateral orchiectomy is likely to be the most cost-effective androgen suppression strategy. Combined androgen blockade is the least economically attractive option, yielding small health benefits at high relative costs (Bayoumi et al 2000).

\section{Complications of hormonal therapy}

The common side effects of hormonal manipulation are hot flushes. Changes in the hormonal balance induced by hormonal manipulation in men with prostate cancer can increase the likelihood of gynecomastia, which usually resolves spontaneously after cessation of hormonal manipulation during the first year (Kumar et al 2005).

Men with prostate cancer who are initiating ADT have a 5- to 10-fold increased loss of bone density at multiple skeletal sites compared with either healthy controls or men with prostate cancer who are not on ADT. Bone loss is maximal in the first year after initiation of ADT, suggesting initiation 
of early preventive therapy (Greenspan et al 2005; Shahinian et al 2005). Hormone therapy does not appear to cause clinically significant changes in depression among men with locally advanced prostate cancer. However, fatigue increased significantly over the study period (Koupparis et al 2004).

The current data suggest that men with prostate cancer who are receiving long-term ADT are at risk for developing insulin resistance, hyperglycemia (Basaria et al 2006), and the occurrence of metabolic syndrome (Braga-Basari et al 2006), thus leading to an increased risk of cardiovascular complications.

Compared with normal men, total and free testosterone levels during treatment were 1.8-fold and 2.3-fold higher in obese men. These differences may contribute to the association between obesity and increased prostate cancer mortality (Smith 2007), loss of sexual desire, erectile dysfunction, and anemia.

Pituitary adenomas (Massoud et al 2006) together with subcutaneous granulomas (Whitaker et al 2002) mimicking metastatic metastatic nodules have also been described with ADT.

\section{Leuprorelin Chemical composition and different formulas}

Natural LHRH was first isolated and identified in 1971 (Schally et al 1971). Leuprorelin (leuprolide acetate) was first synthesized in 1974 by Takeda Chemical Industries, Japan (Fujino et al 1974).

Leuprorelin is a synthetic non-peptide analogue of naturally occurring porcine LHRH. It has a longer half-life than natural LHRH due to its enhanced binding affinity and increased resistance to peptidase degradation. At least two alterations in chemical structure serve to enhance the biologic activity of GnRH. These alterations include substitution of a D-amino acid for the glycine molecule at position 6 and deletion of the glycine molecule at position 10, and usually replacement by an N-ethylamide group (Monahan et al 1973). Leuprorelin is 80 times more potent than natural LHRH (Chrisp and Sorkin 1991).

Leuprorelin is orally inactive and originally was generally given subcutaneously or intramuscularly; leuprorelin $1 \mathrm{mg}$ was given by daily injection. However, a depot formulation was soon developed to enable convenient subcutaneous or intramuscular injection at 1-month intervals. The clinical benefit of treating prostate cancer with LHRH analogues was reported from 1982 (Tolis et al 1982).
Leuprorelin was initially administered subcutaneously to men with metastatic prostate cancer as a daily 1-mg injection, starting in 1985.

The monthly depot was first launched in Europe in France in April 1989, and now is well established as the leading LHRH analogue. Since the publication of earlier reviews (eg, Chrisp and Sorkin 1991), new formulations have also been developed to maximize flexibility and convenience of administration for both doctor and patient.

Microsphere technology enables leuprorelin to be given as a depot formulation. Leuprorelin microspheres range in mean diameter between 10 and $20 \mathrm{~mm}$ for the 1-month depot and between 10 and $30 \mathrm{~mm}$ for the 3-month depot. Clinically, this means that leuprorelin can be given as a liquid injection through a fine-gauge needle using conventional injection techniques.

Sustained-release parenteral depot formulations, in which the hydrophilic leuprorelin is entrapped in biodegradable highly lipophilic synthetic polymer microspheres, have been developed to avoid daily injections (Sharifi et al 1997; Periti et al 2002). In-situ forming drug delivery systems are prepared by dissolving a drug and a biodegradable polymer (poly (D, L-lactide-co-glycolide; PLGA) in a biocompatible organic solvent. In clinical studies of prostatic cancer, use of the depot formulation has effectively reduced the dose required to as low as one-eighth of that needed for administration by daily injection (Togushi 1992).

Three- and 4-month formulations of leuprorelin were approved by the FDA for this indication in 2002 and 2003. Within a few years of its introduction, the 3-month depot accounted for $45 \%$ of the LHRH agonist market, and the 4-month formulation accounted for $40 \%$ of the market in its first year.

The development of depot forms of the LHRH agonists provided a well accepted approach to effective castration. Current formulations of 3- or 4-month (or longer) preparations are widely utilized; the most recent addition is the 6month formula. Other benefits of the LHRH agonists include no cardiovascular toxicity and the fact that the "castration" is reversible.

Subcutaneous implants have been developed; the implant is designed to be removed after 12 months, and then another implant can be inserted for continued therapy.

Implants require a surgical incision and have greater injection site reactions; however, patients avoid multiple injections. The leuprorelin implant $\left(\right.$ Viadur $\left.^{\circledR}\right)$ effectively suppressed testosterone concentrations to less than the castrate threshold and maintained that suppression throughout 
the study period (Fowler et al 2000a). Some authors claimed testosterone suppression to the castrate range of $100 \%$ (Fowler et al 2000b; Mark 2003).

Histrelin acetate $50 \mathrm{mg}$ subdermal implant (Vantas ${ }^{\circledR}$ ) also seems to achieve similar results in men with advanced prostatic cancer. The hydrogel implant provided consistent delivery of histrelin over 1 year. Testosterone suppression was maintained throughout the 52 weeks after implantation in more than $99 \%$ of patients. No testosterone or LH surge was observed with re-implantation. PSA, a secondary end point for effectiveness, was also suppressed significantly from baseline (Schlegel 2006).

\section{Pharmacokinetics}

After injection of the 1-month depot formulation of leuprorelin $3.75 \mathrm{mg}$, peak serum levels are achieved within 1 hour, followed by a rapid fall over the next 24 hours. A dose-dependent plateau is maintained over at least 5 weeks, representing a constant rate of release of leuprorelin from the copolymer (Mazzei et al 1990).

As with the 1-month injection, the 3-month injection $(11.25 \mathrm{mg})$, results in an initial rise in serum levels of leuprorelin, followed by continuous linear release. A serum level of about $200-287 \mathrm{pg} / \mathrm{mL}$ is maintained over at least 3 months (Wechsel et al 1996) (equivalent to that achieved with a 1-month dose of $3.75 \mathrm{mg}$ after repeated injections).

\section{Mechanism of action}

Leuprorelin acts as a potent inhibitor of gonadotropin secretion when given continuously in therapeutic doses. Animal and human studies indicate that after an initial stimulation as with other LHRH analogues (3-4 days), chronic administration of leuprorelin suppresses testicular and ovarian steroidogenesis. In humans, administration of leuprorelin initially increases circulating levels of LH and FSH, leading to a transient increase in levels of the gonadal steroids. However, continuous administration of leuprorelin decreases levels of LH and FSH, and subsequently reduces testosterone. These decreases occur within 2-4 weeks after initiation of treatment.

To obtain optimal therapeutic effect against androgendependent tumor cells, serum testosterone levels must be reduced to castrate levels ( $=50 \mathrm{ng} / \mathrm{dL}$ ) (Fergusson 1957). This level can be achieved by a 1-month depot injection of $3.75 \mathrm{mg}$ leuprorelin (Whitaker et al 2002) or by at 3-month depot injection of $11.25 \mathrm{mg}$ (Khan and O'Brien 1998), or other new depot formulations.
GnRH agonist administration was shown by Redding and Schally to reduce the growth of prostate tumors in rats (Redding and Schally 1983). Early clinical studies in metastatic or advanced prostate cancer established the efficacy of daily s.c. injection of leuprorelin $(1-20 \mathrm{mg})$ in suppressing testosterone levels, delaying tumor progression, and alleviating symptoms of locally advanced and metastatic prostate cancer (Trachtenberg 1983; Yamanak et al 1984). This effect is reversible upon discontinuation of drug therapy and this therapeutic approach has now replaced surgical castration.

\section{Comparative studies on other androgen suppression modalities (Table 3 ): comparison of different depot formulas}

The US Food and Drug Administration (FDA) has emphasized the importance of testosterone in prostate cancer therapy by utilizing decrease in testosterone associated with ADT as a surrogate endpoint for prostate cancer treatment (Brawerr 2001). It is intriguing that the agency uses testosterone and not PSA level in this regard. Therapies directed at treating prostate cancer on a hormonal basis need only to demonstrate achievement of castrate levels of testosterone for approval by the FDA.

Another requirement of $\mathrm{GnRH}$ agonists and other endocrine therapies for prostate cancer is the ability to maintain castration levels of testosterone while on long-term therapy. Different formulas have been proven to be meet those criteria (Table 4). Selecting the best product may be based on: patient comfort, side effects or injection-site reactions, ease of use such as patient preparation, time, and staffing required for administration.

\section{Six-month formulation of leuprorelin depot (Eligard ${ }^{\circledR} 45-\mathrm{mg}$ )}

Six-month leuprorelin acetate (Eligard ${ }^{\circledR} 45-\mathrm{mg}$; Atrix Laboratories) is a new formulation for the palliative treatment of advanced prostate cancer.

In recent study conducted by Crawford et al (2006), the 6month depot formulation of leuprorelin 45-mg $\left(\right.$ Eligard $\left.^{\circledR}\right)$ was evaluated clinically in a 12-month, open-label, multicenter study in patients with prostate cancer. The mean time required to reach castrate $\mathrm{T}$ levels $(<50 \mathrm{ng} / \mathrm{dL})$ was 21 days, $99 \%$ had 12-month testosterone (T) levels $<50 \mathrm{ng} / \mathrm{dL}$, and $88 \%$ patients had T levels $<20 \mathrm{ng} / \mathrm{dL}$. Mean PSA levels decreased from $39.8 \pm 21.5 \mathrm{ng} / \mathrm{mL}$ at baseline to $1.2 \pm 0.3 \mathrm{ng} / \mathrm{mL}$ at 12 months. 
Table 3 Leuprorelin: comparative studies to other androgen suppression modalities

\begin{tabular}{|c|c|c|c|}
\hline & $\begin{array}{l}\text { Testosterone lowering/ } \\
\text { blocking method }\end{array}$ & Comment & Reference \\
\hline \multirow[t]{4}{*}{ Leuprorelin } & Orchietomy & $\begin{array}{l}\text { Equivalent, orchiectomy, cost } \\
\text { effective but associated } \\
\text { with psychological complications }\end{array}$ & $\begin{array}{l}\text { (Parmar 1985; Cassileth 1989; } \\
\text { Iversen 1998; McLeod 2003) }\end{array}$ \\
\hline & $\begin{array}{l}\text { Estrogens (DES } 3 \mathrm{mg} \text { ) } \\
\text { vs I mg/day leuprorelin }\end{array}$ & $\begin{array}{l}\text { Equivalent, less cardiovascular } \\
\text { side effects with leuprorelin. }\end{array}$ & (LSG I984) \\
\hline & Other LHRH agonists & $\begin{array}{l}\text { No meaningful difference among } \\
\text { the various approved GnRH agonists. }\end{array}$ & (Seidenfeld 2000) \\
\hline & LHRH antagonists (aberalix) & $\begin{array}{l}\text { Short time to testosterone } \\
\text { suppression. } \\
\text { No testosterone surge with aberalix. } \\
\text { Safety is comparable to that of } \\
\text { LHRH agonists with or without anti-androgens. }\end{array}$ & (McLeod 200I; Debruyne 2004) \\
\hline
\end{tabular}

Abbreviation: LHRH, luteinizing hormone-releasing hormone.

The 6-month formula of leuprorelin is the new addition which has a number of advantages over shorter-acting depot products, while reducing the need to schedule actual treatment time to only twice yearly.

Patients who may benefit from include those who:

- Are stable and well controlled on palliative therapy

- Travel for extended periods of time

- Have difficulty getting to the physician's office (eg, due to

limited mobility or long travel distance)

- Receive an LHRH agonist as neoadjuvant therapy.

Moreover, the change in Medicare reimbursement (Painter 2005) for injections to "budget neutral" removes any incentive for favoring a formulation that is given more often over one that is given every 6 months. Of the urologists polled, $77 \%$ said that they were likely to use a 6-month depot rather than the shorter treatment regimens currently available. This novel delivery system allows for a lowvolume injection, with very small changes in volume with increased dosage.

The Atrige ${ }^{\circledR}$ Delivery System is composed of a biodegradable polymer (DL-lactide-coglycolide) dissolved in a biocompatible liquid solvent (N-methyl-2-pyrrolidone, or NMP). Because of its larger volume, leuprorelin depot is typically injected into the buttocks, necessitating the use of a treatment room. Patients receiving Lupron ${ }^{\circledR}$ Depot may experience pain at the injection site lasting up to 2 days, large abscesses, and bruising. However, there was no statistically significant difference in pain experienced on injection of goserelin and leuprorelin when patients were unaware of needle size (Montgomery et al 2005).

\section{Conclusion}

After seven decades, ADT has stood the test of time and gained its place as the mainstay of treatment for advanced and metastatic prostate cancer. It has relieved the symptoms and prolonged the life of many patients. Its discovery and refinement have brought two Nobel prizes to the medical community, first with the seminal work of Charles Higgins on the influence of the endocrine system on the development of a human malignancy in 1966, and then in 1977 with Andrew Schally's work on the hypothalamic hormones.

ADT went through several steps and refinement processes to reach its current status. In the 1940s the only option available was the irreversible castration through orchiectomy or the administration of female hormones, today the options are myriad.

The availability of long-acting synthetic LHRH agonists in the 1980s revolutionized the hormonal treatment of

Table 4 Leuprorelin formulas and testosterone suppression

\begin{tabular}{|c|c|c|c|c|}
\hline \multirow[t]{2}{*}{ Leuprorelin formula } & \multirow[t]{2}{*}{ Injection volume $(\mathrm{mL})$} & \multicolumn{2}{|c|}{ Testosterone castrate level } & \multirow[t]{2}{*}{ Authors } \\
\hline & & 50 ng/dL & $20 \mathrm{ng} / \mathrm{dL}$ & \\
\hline $7.5 \mathrm{mg}$ monthly & 0.250 & $100.0 \%$ & $97.5 \%$ & Perez-Mareno 2002 \\
\hline \multirow[t]{2}{*}{22.5 (3 month) } & 0.375 & $98 \%$ & & Berges 2006 \\
\hline & & $98 \%$ & $84 \%$ & Chu 2002 \\
\hline $30 \mathrm{mg}$ (4 month) & 0.500 & $96 \%$ & & Sharifi 1998 \\
\hline 45.0 mg (6 month) & 0.375 & $99 \%$ & $88 \%$ & Crawford 2006 \\
\hline
\end{tabular}


prostate cancer, enabling many men to avoid the emotional and psychological effects of surgical castration. The depot formulas have gained wide acceptance from both patients and physicians.

The 6-month formula of leuprorelin represents a new addition to the armentarium that has a number of advantages over shorter-acting depot products. It suppresses the testosterone to the castrate level in the majority of patients completing treatment without any breakthrough responses.

Compared with a 3-month depot, the 6-month depot is associated with two rather than four opportunities for patients to lose therapeutic effect if they delay their injection beyond the formulation's normal duration, thus improving the patient's compliance to therapy and quality of life.

The limited number of injections reduces the anxiety due to physician's office visit and fear of pain; injection takes minimal time which is the most desirable option from the nursing standpoint. The drug is well tolerated while maintaining a side effect profile comparable to other products in its class.

These advantages coupled with the recent change to Medicare legislation will make long-duration formulation an attractive option for physicians, and will certainly tip the balance in favor of this option in treating prostate cancer patients fulfilling the criteria for receiving such products.

\section{References}

Akaza H. 2006. Trends in primary androgen depletion therapy for patients with localized and locally advanced prostate cancer: Japanese perspective. Cancer Sci, 97:243-7.

Akaza H, et al. 2006. Efficacy of primary hormone therapy for localized or locally advanced prostate cancer:results of a 10-year follow-up. BJU Int, 98:573-9.

Androutsos G. 1998. John Hunter (1728-1793):fondateur de la chirurgie scientifique et précurseur de l'urologie. Prog Urol, 8:1087-96.

Barqawi A, Akduman B, Abouelfadel Z, et al. 2003.The use of flutamide as a single antiandrogen treatment for hormone-refractory prostate cancer. BJU Int, 92:695-8.

Barqawi AB, Moul JW, Ziada A, et al. 2003. Combination of low-dose flutamide and finasteride for PSA-only recurrent prostate cancer after primary therapy. Urology, 62:872-6.

Basaria S, Muller DC, Carducci MA, et al. 2006. Hyperglycemia and insulin resistance in men with prostate carcinoma who receive androgen-deprivation therapy. Cancer, 106:581-8.

Bayoumi AM, Brown AD, Garber AM. 2000. Cost-effectiveness of androgen suppression therapies in advanced prostate cancer. $J$ Natl Cancer Inst, 92:1731-9.

Beer TM. 2004. Experimental use of GnRH antagonists as second-line hormonal therapy. Rev Urol, 6:S33-8.

Berges R, Bello U. 2006. Effect of a new leuprorelin formulation on testosterone levels in patients with advanced prostate cancer. Curr Med Res Opin, 22:649-55.

Boccon-Gibod L, Fournier G, Bottet P, et al. 1997. Flutamide versus orchidectomy in the treatment of metastatic prostate carcinoma. Eur Urol, 32:391-5.
Braga-Basaria M, Dobs AS, Muller DC, et al. 2006. The metabolic syndrome in men with prostate cancer undergoing long term androgen deprivation therapy. J Clin Oncol, 24:3979-83.

Brawer MK. 2001. The evolution of hormonal therapy for prostatic carcinoma. Rev Urol, 3:S1-11.

Burchardt M, Burchardt T, Chen MW, et al. 2000. Vascular endothelial growth factor-A expression in the rat ventral prostate gland and the early effects of castration. Prostate, 43:184-94.

Buttyan R, Ghafar MA, Shabsigh A. 2000. The effects of androgen deprivation on the prostate gland:cell death mediated by vascular regression. Curr Opin Urology, 10:415-20.

Byar DP, Corle DK. 1988. Hormone therapy for prostate cancer: results of the Veterans Administration Cooperative Urological Research Group studies. NCI Monogr, 165-170.

Cassileth BR 1989. Patients' choice of treatment in stage D prostate cancer. Urology, 33:57-59.

Cavarretta ITR, Culig Z, Klocker H, et al. 2005. Novel experimental therapeutic approaches for prostate cancer. EUA Update Series, $3: 227-39$.

Chodak GW. 2004. A critical review of maximal androgen blockade for advanced prostate cancer. Rev Urol, 6:18-23

Chodak GW. 2005. Maximum androgen blockade: a clinical update. Rev Urol, 7:13-17.

Chrisp P, Sorkin EM. 1991. Leuprorelin:a review of its pharmacology and therapeutic use in prostatic disorders. Drugs Aging, 1:487-509.

Chu FM, Jayson M, Dineen MK, et al. 2002. A clinical study of $22.5 \mathrm{mg}$. La-2550: A new subcutaneous depot delivery system for leuprolide acetate for the treatment of prostate cancer. $J$ Urol, 168:1199-203.

Conn PM, Roger SC, Seay SG. 1984. Biphasic regulation of gonadotropin-releasing hormone receptor by receptor micro-aggregation and intracellular Ca2 levels. Med Pharmacol, 25:51-55.

Coppage WS Jr, Cooner AE. 1965. Testosterone in human plasma. N Engl $J$ Med, 273:902-7.

Crawford ED, Eisenberger MA, McLeon DG, et al. 1989. A controlled trial of leuprolide with and without flutamide in prostatic carcinoma. N Engl J Med, 321:419-24.

Crawford ED, Sartor O, Chu F, et al. 2006. A 12-month clinical study of LA-2585 (45.0 mg):a new 6-month subcutaneous delivery system for leuprolide acetate for the treatment of prostate cancer. $J$ Urol, 175:533-6.

Debruyne FMJ. 2004. Gonadotropin-releasing hormone antagonist in the management of prostate cancer. Rev Urol, 6:S25-32.

Denis LJ, Keuppens F, Smith PH, et al. 1998. Maximal androgen blockade: final analysis of EORTC phase III trial 30853. Eur Urol, 33:144-51.

Denmeade SR, Isaacs JT. 2004. Development of prostate cancer treatment: the good news. Prostate, 58:211-24.

Denmeade SR, Lin XS, Isaacs JT. 1996. Role of programmed (apoptotic) cell death during the progression and therapy for prostate cancer Prostate, 28:251-65.

Fergusson JD. 1957. Implantation of radioactive material into the pituitary for the control of prostatic cancer. Br J Urol, 29:215-22.

Fowler JE, Flanagan M, Gleason DM, et al. 2000a. Evaluation of an implant that delivers leuprolide for 1 year for the palliative treatment of prostate cancer. Urology, 55:639-42.

Fowler JE, Gottelsman JE Reid CF, et al. 2000b. Safety and efficacy of an implantable leuprolide delivery system in patients with advanced prostate cancer. $J$ Urol, 164:730-4.

Franck-Lissbrant I, Haggstrom S, Damber JE, et al. 1998. Testosterone stimulates angiogenesis and vascular re-growth in the ventral prostate in castrated adult rats. Endocrinology, 139:451-6.

Freedland SJ, Partin AW. 2005. Early hormonal therapy for prostate cancer: the good, the bad and the ugly. Rev Urol, 7:187-8.

Fujino M, Fukuda T, Shinagawa S et al. 1974. Synthetic analogs of luteinizing hormone releasing hormone (LH-RH) substituted in position 6 and 10. Biochem Biophys Res Commun, 60:406-13. 
Gleave ME, Goldenberg SL, Chin JL, et al. 2001. Randomized comparative study of 3 versus 8 -month neoadjuvant hormonal therapy before radical prostatectomy: biochemical and pathological effects. $J$ Urol, 166:500-6.

Greenspan SI, Coates P, Sereika SM, et al. 2005. Bone loss after initiation of androgen deprivation therapy in patients with prostate cancer. J Clin Endoc Metab, 90:6410-7.

Hall EJ. 2000. Radiobiology for radiobiologist (5th ed). Philadelphia: Lippincot Wilkins.

Home E. 1811. Practical observations on the treatment of the diseases of the prostate gland. London: Nicol.

Huggins C, Clark PJ. 1940. Quantitative studies of prostatic secretion. II. The effect of castration and of estrogenic injections on the normal and on the hyperplasic prostate glands of dogs. J Exp Med, 72:747-61.

Huggins C, Hodges CU. 1941. Studies on prostate cancer:the effect of castration, of estrogen and of androgen injection on serum phosphatases in metastatic carcinoma of the prostate. Cancer Res, 1:293.

Huggins C, Scott WW 1945. Bilateral adrenalectomy in prostatic cancer: clinical features and urinary excretion of 17-ketosteroids and estrogen. Ann Surg, 122:1031-41.

Huggins C, Stevens RE Jr, Hodges CV. 1941. Studies in prostatic cancer. Arch Surg, 43:209-23.

Isaacs JT. 1984. Antagonistic effect of androgen on prostatic cell death. Prostate, 5:545-57.

Isaacs JT. 1994. Role of androgens in prostate cancer. Vitam Horm, 49:433-502.

Iversen P. 1998. Orchidectomy and oestrogen therapy revisited. Eur Urol, 34:7-11.

Iversen P, Melezinek I, Schmidt A. 2001. Nonsteroidal antiandrogens:a therapeutic option for patients with advanced prostate cancer who wish to retain sexual interest and function. BJU Int, 87:47-56.

Jacobi GH. 1983. Intramuscular cyproterone acetate for advanced prostatic carcinoma:results of the first multicentre trial. In Androgens and antiandrogens. Netherlands: Schering. pp. 161-70.

Janoff DM, Peterson C, Mongoue-Tchokote S, et al. 2005. Value of androgen ablation in conjunction with radiation for locally advanced Pca: clinical outcomes of androgen deprivation as the sole therapy for localized and locally advanced prostate cancer. BJU Int, 96:503-7.

Keyes EL, Ferguson RS. 1936. Treatment of malignant tumors of the prostate. In Keyes EL, Ferguson RS (eds). Urology (6th ed). New York: Appleton-Century. pp. 425-6.

Khan MS, O'Brien A. 1998. An evaluation of pharmacokinetics and pharmacodynamics of leuprorelin acetate $3 \mathrm{M}$-depot in patients with advanced and metastatic carcinoma of the prostate. Urol Int, 60:33-40.

Kirk D. 2000. Immediate vs. delayed hormone treatment for prostate cancer: how safe is androgen deprivation? Brit J Uro Int, 86:220. Abstract MP6.1.07.

Kirk D. 2006. Comment on: Can androgen deprivation be considered a primary treatment for prostate cancer? Nat Clin Pract Urol, 3:127.

Koupparis A, Ramsden A, Persad R. 2004. Cognitive effects of hormonal treatment for prostate cancer. BJU Int, 93:915-16.

Kumar RJ, Al Barqawi, Crawford, ED. 2005. Adverse events associated with hormonal therapy for prostate cancer. Rev Urol, 7:37-43.

Labrie F, Candas B, Gomez JL, et al. 2002. Can combined androgen blockade provide long-term control or possible cure of localized prostate cancer? Urology, 60:115-9.

Leibovitz RL, Tucker SJ. 2001. Treatment of localized prostate cancer with intermittent triple androgen blockade:preliminary results in 110 consecutive patients. Oncologist, 6:177-8.

Lowe FC, Bamberger MH. 1990. Indications for use of ketoconazole in management of metastatic prostate cancer. Urology, 36:541.

[LPG] The Leuprolide Study Group. 1984. Leuprolide versus diethylstilbestrol for metastatic prostate cancer. $N$ Engl J Med, 311:1281-6.

[LSG] The Leuprolide Study Group. 1984. Leuprolide versus diethylstilbesterol for metastatic prostate cancer. $N$ Engl J Med, 311:1281-6.

Lyons JA, Kupelian PA, Mohan DS, et al. 2000. Importance of high radiation doses (72 Gy or greater) in the treatment of stage T1-T3 adenocarcinoma of the prostate. Urology, 55:85-90.
Malone S, Perry G, Eapen L, et al. 2007. Mature results of the Ottawa Phase II study of intermittent androgen-suppression therapy in prostate cancer: clinical predictors of outcome Prostate-specific Antigen-only Recurrence. Int J Radiat Oncol Biol Phys, 68:699-706.

Malone S, Perry G, Segal R, et al. 2005. Long-term side-effects of intermittent androgen suppression therapy in prostate cancer:results of a phase II study. BJU Int, 96:514-20.

Mariani AJ, Glover M, Arita S. 2001. Medical versus surgical androgen suppression therapy for prostate cancer:a 10-year longitudinal cost study. J Urol, 165:104-7.

Mark LS. 2003. Luteinizing hormone-releasing hormone agonists in the treatment of men with prostate cancer:timing, alternatives, and the 1-year implant. Urology, 62:36-42.

Massoud W, Paparel P, Lopez JG, et al. 2006. Discovery of a pituitary adenoma following a gonadotropin-releasing hormone agonist in a patient with prostate cancer. Int J Urol, 13:303-4.

Mazzei T, Mini E, Rizzo M, et al. 1990. Human pharmacokinetic and pharmacodynamic profiles of leuprorelin acetate depot in prostatic cancer patients. J Int Med Res, 18:42-56.

McLeod D, Zinner N, Tomera K, et al. 2001. Aberalix Study Group.A phase 3, multicenter, open-label, randomized study of abarelix versus leuprolide acetate in men with prostate cancer. Urology, 58:756-61.

McLeod DG. 1997. Tolerability of nonsteroidal antiandrogens in the treatment of advanced prostate cancer. Oncologist, 2:18-27.

McLeod DG. 2003. Hormonal therapy:historical perspective to future direction. Urology, 61:3-7.

Mercader M, Sengupta S, Bodner B K, et al. 2007. Early effects of pharmacological androgen deprivation in human prostate cancer. BJU Int, 99:60-67.

Messing EM, Monola J, Sarodsy M, et al. 1999. Immediate hormonal therapy compared with observation following radical prostatectomy and pelvic lymphadenectomy in men with node-positive prostate cancer. $N \mathrm{Engl}$ J Med, 341:1781-8.

Migliari R, Muscas G, Murru M, et al. 1999. Antiandrogens:a summary review of pharmacodynamic properties and tolerability in prostate cancer therapy. Arch Ital Urol Androl, 71:293-302.

Miller K, Steiner U, Lingnau et al. 2007. Randomized prospective study of intermittent versus continuous androgen suppression in advanced prostate cancer. $A S C O$, Abstract 50-15.

Monahan MW, Amoss MS, Anderson HA, et al. 1973. Synthetic analogs of the hypothalamic luteinizing hormone releasing factor with increased agonist or antagonist properties. Biochemistry, 12:4616-20.

Montgomery BS, Borwell JP, Higgins DM. 2005. Does needle size matters? Patient experience with luteinizing hormone releasing hormone analogue. Prostate Cancer Prostatic Dis, 8:66-8.

Morote J, Esquena S, Abascal JM, et al. 2006. Failure to maintain a suppressed level of serum testosterone during long-acting depot luteinizing hormone-releasing hormone agonist therapy in patients with advanced prostate cancer. Urol Int, 77:135-8.

Moul JW, Wu H, Sun L et al. 2004. Early versus delayed hormonal therapy for prostate specific antigen only recurrence of prostate cancer after radical prostatectomy $J$ Urol, 171:1141-7.

Moul JW. 2004 The evolving definition of advanced prostate cancer. Rev Urol, 6:S10-16.

[MRC] The Medical Research Council Prostate Cancer Working Party Investigators Group. 1997. Immediate versus deferred treatment for advanced prostatic cancer:initial results of the Medical Research Council Trial. Br J Urol, 79:235-46.

Murphy WT, Schwippert H. 1951. Pituitary irradiation in prostatic cancer. Radiology, 56:376-80.

Newling DWW. 1996. Anti-androgens in the treatment of prostate cancer. Br J Urol, 77:776-84.

Oefeiein MG, Comum R. 2000. Failure to achieve castrate levels of testosterone during luteinizing hormone releasing hormone agonist therapy:the case for monitoring serum testosterone and a treatment decision algorithm. J Urol, 164:726-9. 
Oefelein MG, Feng A, Scolieri MJ, et al. 2000. Reassessment of the definition of castrate levels of testosterone:implications for clinical decision making. Urology, 56:1021-4.

Ornstein DK, Beiser JA, Andriole GL. 1999. Anaemia in men receiving combined finasteride and flutamide therapy for advanced prostate cancer. BJU Int, 83:43-6.

Painter M R. 2005. Reimbursement issues with hormonal therapies for prostate cancer. Rev Urol, 7:S44-7.

Parmar H, Lightman SL, Allen L, et al. 1985:Randomised controlled study of orchidectomy vs. long-acting D-Trp-6-LHRH microcapsules in advanced prostatic carcinoma. Lancet, 2:1201-5.

Pavone-Macaluso M. 1994. Flutamide monotherapy versus combined androgen blockade in advanced prostate cancer. Interim report of an Italian multicentre, randomised study. SIU 23rd Congress: A354.

Peehl DM. 2001. Basic science of hormonal therapy for prostate cancer. Rev Urol, 3:15-22.

Perez-Mareno R, Chu FM, Gleason D, et al. 2002. A six-month, open-label study assessing a new formulation of leuprolide $7.5 \mathrm{mg}$ for suppression of testosterone in patients with prostate cancer. Cli Ther, 24:1902-14.

Periti P, Mazzei T, Mini E. 2002. Clinical pharmacokinetics of depot leuprorelin. Clin Pharmacokinet, 41:485-504.

Petrylak DP. 2005, The Current role of chemotherapy in metastatic hormonerefractory prostate cancer. Urology, 65:3-8.

Petrylak DP. 2007. New paradigms for advanced prostate cancer. Rev Urol, 9:3-12.

Pilepich MV, et al. 2005. Androgen suppression adjuvant to definitive radiotherapy in prostate carcinoma - long-term results of phase III RTOG 85-31. Int J Radiat Oncol Biol Phys, 61:1285-90.

Pont A. 1987. Long term experience with high dose ketoconazole therapy in patients with D2 prostatic carcinoma. J Urol, 137:902.

Pound R, Partin AW, Eisenberger MA, et al. 1999. Natural history of progression after PSA elevation following radical prostatectomy. JAMA, 281:1591-7.

Redding TW, Schally AV. 1983. Inhibition of mammary tumor growth in rats and mice by administration of agonistic and antagonistic analogs of luteinizing hormone-releasing hormone. Proc Natl Acad Sci USA, $80: 1459-62$

Ryan CJ, Elkin EP, Small EJ, et al. 2006. Reduced incidence of bony metastasis at initial prostate cancer diagnosis: data from CaPSURE. Urol Oncol, 24:396-402.

Sandford NL, Searle JW, Kerr JF. 1984. Successive waves of apoptosis in the rat prostate after repeated withdrawal of testosterone stimulation. Pathology, 16:406-10.

Sandow J, von Rechenberg W, Engelbart K. 1988. Pharmacological studies on androgen suppression in therapy of prostate carcinoma. Am J Clin Oncol, 11:S6-10.

Satterthwaite RW, Hill JH, Packard EE. 1941. Experimental and clinical evidence on the role of the 17 keto-steroids in prostatic carcinoma. J Urol, 46:1149-54.

Schally AV, Arimura A, Baba Y, et al. 1971. Isolation and properties of the FSH and LH-releasing hormone. Biochem Biophys Res Commun, 43:393-9.

Schlegel PN. 2006. Histrelin Study Group. Efficacy and safety of histrelin subdermal implant in patients with advanced prostate cancer. J Urol, 175:1353-8

Scholz M, Jennrich R, Strum S, et al. 2005. Long-term outcome for men with androgen independent prostate cancer treated with ketoconazole and hydrocortisone. $J$ Urol, 173:1947-952.

Schröder FH. 2002. Hormonal therapy of prostate cancer. In Walsh PC, Retik AB, Vaughn ED Jr, et al. (eds). Campbell's urology (8th ed). Philadelphia: WB Saunders. pp. 3182-208.

See WA. 2003. Adjuvant hormone therapy after radiation or surgery for localized or locally advanced prostate cancer. Curr Treat Options Oncol, 4:351-62.

Seidenfeld J, Samson DJ, Hasselblad V, et al. 2000. Single-therapy androgen suppression in men with advanced prostate cancer:a systematic review and meta-analysis. Ann Intern Med, 132:566-77.
Shabisgh A, Tanji N' D'Agati V, et al. 1999. Early effects of castration on the vascular system of the rat ventral prostate gland. Endocrinology, 140:1920-1926.

Shahinian VB, Kuo YF, Freeman JL, et al. 2005. Risk of fracture after androgen deprivation for prostate cancer. $N$ Engl $J$ Med, 352:154-64.

Sharifi R, Knoll LD, Smith J, et al. 1998. Leuprolide acetate (30-mg depot every four months) in the treatment of advanced prostate cancer. Urology, 51:271-6.

Sharifi R, Ratanwong C, Jung A, et al. 1997. Therapeutic effects of leuprorelin microspheres in prostate cancer. Adv Drug Deliv Rev, 28:121-36.

Silverberg GD, Britt RH. 1979. Trans-sphenoidal hypophysectomy in the treatment of metastatic breast and prostate carcinoma. West J Med, 130:191-5.

Small E J, Ryan CJ. 2006. The case for secondary hormonal therapies in the chemotherapy age. $J$ Urol, 176:S66-71.

Smith MR 2007. Obesity and sex steroids during gonadotropin-releasing hormone agonist treatment for prostate cancer. Clin Cancer Res, 13:241-5

Sogani PC, Ray B, Whitmore WF. 1975. Advanced prostatic carcinoma. Urology, 6:164-6.

Studer U, Whelan P, Albrecht W, et al. 2006. Immediate or deferred androgen deprivation for patients with prostate cancer not suitable for local treatment with curative intent: European Organization for Research and Treatment of Cancer Trial 30 891. J Clin Oncol, 24:1868-76.

Tabata K, et al. 2006. 8-month neoadjuvant hormonal therapy before radical prostatectomy for high-risk prostate cancer. Nippon Hinyokika Gakkai Zasshi, 97:712-8.

Taneja SS. 2003. A multidisciplinary approach to the management of hormone-refractory prostate cancer. Rev Urol, 5:85-91.

Thompson IM, 2001. Flare associated with LHRH-agonist therapy. Rev Urol, 3:10-14.

Togushi H. 1992. Formulation study of leuprorelin acetate to improve clinical performance. Clin Ther, 14:121-30.

Tolis G, Ackman D, Tellos S, et al. 1982. Tumour growth inhibition in patients with prostaic carcinoma treated with luteinising hormone releasing hormone agonists. Proc Nat Acad Sci USA, 79:1658-62.

Trachtenberg J, Gittleman M, Steidle C, et al. 2002. A phase 3, multicenter, open-label randomized study of abarelix versus leuprolide plus daily antiandrogen in men with prostate cancer. $J$ Urol, 167:1670-4.

Trachtenberg J, Point A. 1983. Ketoconazole: a novel and rapid treatment for advanced prostate cancer. $J$ Urol, 130:152.

Trachtenberg J. 1983. The treatment of metastatic prostatic cancer with a potent luteinizing hormone releasing hormone analogue. $J$ Urol, 129:1149-52

Uchida T, Illing RO, Cathcart PJ, et al. 2006. The effect of neoadjuvant androgen suppression on prostate cancer-related outcomes after highintensity focused ultrasound therapy. BJU Int, 98:770-2.

Usami $\mathrm{M}$, et al. 2007. Bicalutamide $80 \mathrm{mg}$ combined with a luteinizing hormone-releasing hormone agonist (LHRH-A) versus LHRH-A monotherapy in advanced prostate cancer: findings from a phase III randomized, double-blind, multicenter trial in Japanese patients. Prostate Cancer Prostatic Dis, 10:194-201.

Van Loenen AC, Huirne JA, Schats R, et al. 2002. GnRH agonists, antagonists, and assisted conception. Semin Reprod Med, 20:349.

Ward JF, Moul JW. 2005. Biochemical recurrence after definitive prostate cancer therapy. Part I:defining and localizing biochemical recurrence of prostate cancer. Curr Opin Urol, 15:181-6.

Wechsel HW, Zerbib M, Pagano F, et al. 1996. Randomized opabelledled comparative study of the efficacy, safety and tolerability of leuprorelin acetate $1 \mathrm{M}$ and $3 \mathrm{M}$ depot in patients with advanced prostatic cancer. Eur Urol, 30:7-14; discussion 19-21.

Whitaker IS, Fazel MZ, Joshi HB, et al. 2002. Leuprorelin acetate granulomas:recurrent subcutaneous nodules mimicking metastatic deposits at injections sites. BJU Int, 90:350.

White JW. 1895. The results of double castration in hyper-trophy of the prostate. Ann Surg, 22:1-3 
White JW. 1904. The present position of surgery of the hypertrophied prostate. Ann Surg, 40:788-92.

Yamanaka H, Makino T, Kumasaka F, et al. 1984. [Clinical efficacy of (DLeu6)-des Gly-NH2(10)-LHRH ethylamide against prostatic cancer]. Hinyokika Kiyo, 30:545-6.

Young HH II, Kent JR. 1968. Plasma testosterone levels in patients with prostatic carcinoma before and after treatment. J Urol, 99:788-92.

Zietman AL. 2000. The case for neoadjuvant androgen suppression before radiation therapy. Mol Urol, 4:203-8; discussion 215. 